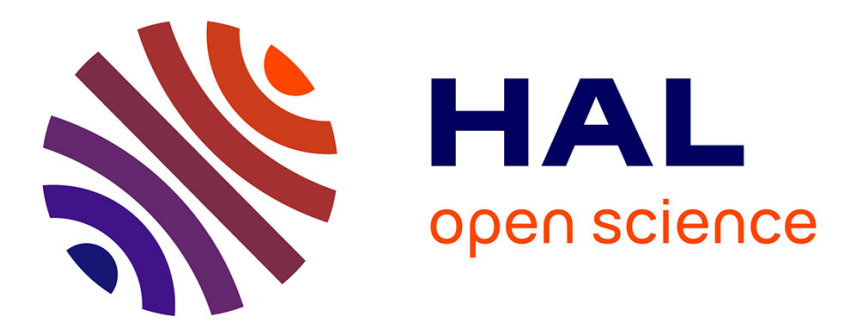

\title{
Unmixing polarimetric radar images based on land cover type before target decomposition
}

\author{
Sébastien Giordano, Grégoire Mercier, Jean-Paul Rudant
}

\section{To cite this version:}

Sébastien Giordano, Grégoire Mercier, Jean-Paul Rudant. Unmixing polarimetric radar images based on land cover type before target decomposition. IGARSS 2014 - 2014 IEEE International Geoscience and Remote Sensing Symposium, Jul 2014, Quebec City, Canada. pp.2790-2793, 10.1109/IGARSS.2014.6947055 . hal-02387155

\section{HAL Id: hal-02387155 \\ https://hal.science/hal-02387155}

Submitted on 29 Nov 2019

HAL is a multi-disciplinary open access archive for the deposit and dissemination of scientific research documents, whether they are published or not. The documents may come from teaching and research institutions in France or abroad, or from public or private research centers.
L'archive ouverte pluridisciplinaire HAL, est destinée au dépôt et à la diffusion de documents scientifiques de niveau recherche, publiés ou non, émanant des établissements d'enseignement et de recherche français ou étrangers, des laboratoires publics ou privés. 


\title{
UNMIXING POLARIMETRIC RADAR IMAGES BASED ON LAND COVER TYPE BEFORE TARGET DECOMPOSITION
}

\author{
Sébastien Giordano ${ }^{1,2}$, Grégoire Mercier ${ }^{3}$, Jean-Paul Rudant ${ }^{4}$ \\ 1. IGN/ENSG/DIAS, Université Paris Est, Marne la Vallée, France \\ 2. IGN/MATIS lab., Université Paris Est, Saint-Mandé, France \\ 3 : Institut Mines-Telecom / Telecom Bretagne, CNRS UMR 6285 Lab-STICC, team CID, Brest, France \\ 4 : Labo.ESYCOM, Université Paris Est,Marne la Vallée, France
}

\begin{abstract}
A new method for unmixing radar polarimetric images with optical images is proposed. It was found that the polarimetric covariance matrix can be unmixed considering a linear model. As a result, this model is used to produce unmixed covariance matrices based on land cover types. We hope to prove that this unmixing of the polarimetric information produce greater information for land cover classification.
\end{abstract}

Index Terms - unmixing, radar, polarimetry, land cover.

\section{INTRODUCTION}

Radar images acquired from space-borne polarimetric sensors are of great interest for land cover classification. The information derived from it is directly related to geometrical or geophysical properties of the objects to be classified. In addition, very high optical images are often available. Countries usually manage optical image repositories supplied with aerial or very high resolution satellite images. The radar polarimetric images are very consistent with creating and updating large scale land cover maps, whereas deriving this information from sub-metric optical images may imply the use of high level image processing algorithms. At an observation level, the combination of polarimetric radar and optical images is expected to produce more reliable results on land cover classification. As a consequence, it may be interesting to explore different methods to merge them for land cover classification.

In [1], observation-based state-of-the-art methods were discussed for optical and radar image fusion. The inadequacy of these methods to merge radar and optical data was noticed as most of them consider the two types of images as being highly correlated. Spatial and spectral unmixing methods,

This work was partially supported thanks to a support from the European Union, the Brittany Region and the Brest Metropole Oceane to the VIGISAT project, in the framework of a FEDER grant Présage \# 32635 and a partnership with CLS for providing the data, under the contracts\# 08 GET 13M and 09 GET 11M. traditionally designed for optical image fusion, were found to be an interesting framework for sharpening radar images with co-registered higher resolution optical images. As a consequence, the idea of unmixing physical radar scattering mechanisms with the optical images was proposed as a suitable means to improve the resolution of the polarimetric radar images. However, the problem that these images are of different types remains to be tackled.

Extracting information from a polarimetric representation (scattering, coherency or covariance matrix) consists in decomposing it with target decomposition algorithms. A review of these methods can be found in [2]. The basis used for decomposition can be related to physical scattering properties of the objects (such as surface, double bounce or volume scattering), or some statistical properties (entropy, anisotropy and alpha angle in the case of Cloude and Pottier decomposition [3]). The problem while using these target decomposition algorithms is that average physical parameters are obtained. As a result, each land cover type of a mixed pixel might not be well described by the average polarimetric parameters. The effect is all the more important as speckle affecting radar observations requires a local estimation of the polarimetric matrices. The original method developed in this paper is the decomposition of the polarimetric information, based on the land cover type. This decomposed polarimetric information is estimated from data before applying usual target decomposition algorithms.

\section{UNMIXING EQUATIONS}

Equations that are used to split off polarimetric information based on land cover type were calculated for the covariance matrix as the polarimetric representation. An extent of Goodman hypotheses of fully developed speckle [4] for the case of two different land cover types: type 0 and type 1 was considered. Within these hypotheses, the covariance matrix was computed knowing that the resolution cell contains independent elementary scatterers from type 0 and 1 in a given $\mu$ pro- 
portion. Equation (1) shows this mixing hypothesis for a radar channel $S_{X Y}$ of the scattering matrix. The covariance matrix observed is then the result of a random walk in the complex plane through the two different types of scatterers. It was found that the covariance matrix can be written with a linear equation (2) depending on $C_{0}$ and $C_{1}$ matrices (covariance matrices of land cover type 0 and land cover type 1) weighted by the proportion of each type of elementary scatterer. The elements of the two matrices $C_{0}$ and $C_{1}$ are explained in equations (3) and (4) using the notation given in equation (5), in the case of a reciprocal $C$ matrix.

$$
S_{X Y}=\sum_{n=1}^{\mu N}\left|S_{0 n_{X Y}}\right| e^{j \phi_{0 n_{X Y}}}+\sum_{m=1}^{(1-\mu) N}\left|S_{1 m_{X Y}}\right| e^{j \phi_{1 m_{X Y}}}
$$

with $X Y=H H, H V, V H$ or $V V$,

$N$ is the number of elementary scatterers and $\mu \in[0,1]$ is the proportion of type 0 and 1 .

\section{PROPOSED ALGORITHM}

Once the formula of the elements of $C_{0}$ and $C_{1}$ are known, the algorithm detailed in figure 1 was designed to estimate them from data. For this first experiment Bare soil and Forested area were considered for land cover types 0 and 1 . The approach developed is to use high level information derived from the optical images to estimate the $\mu$ parameter for each pixel or group of pixels that are taken into account in the target decomposition. It is then assumed that this result is a good estimation of the proportion of elementary scatterers in the resolution cell. In the registration step, local decisions on land cover types were brought together to estimate the $\mu$ parameter. Knowing this proportion, the unmixing algorithm was computed in the radar geometry and elements of $C_{0}$ and $C_{1}$ matrices were estimated over a $\langle M, M\rangle$ radar neighbourhood with a least squares minimisation method. Finally, $C_{0}$ and $C_{1}$ matrices are decomposed with any target decomposition algorithm to retrieve physical parameters of each land cover type class. As a result, these physical parameters should be more reliable for land cover classification, as this unmixing algorithm limits the averaging process before applying the target decomposition.

\section{RESULTS}

This part addresses the issue of testing the designed unmixing algorithm on real data. $25 \mathrm{~cm}$ resolution aerial images were acquired on a study area in Provence (South-East of France) on June 22, 2012. In addition, a Radarsat-2 full polar images was obtained on June 27, 2012 (pixel size in slant range $4,73 m \times 4,76 m$ ). The site chosen to test the algorithm consists of forested and semi-natural areas characterised by agri-

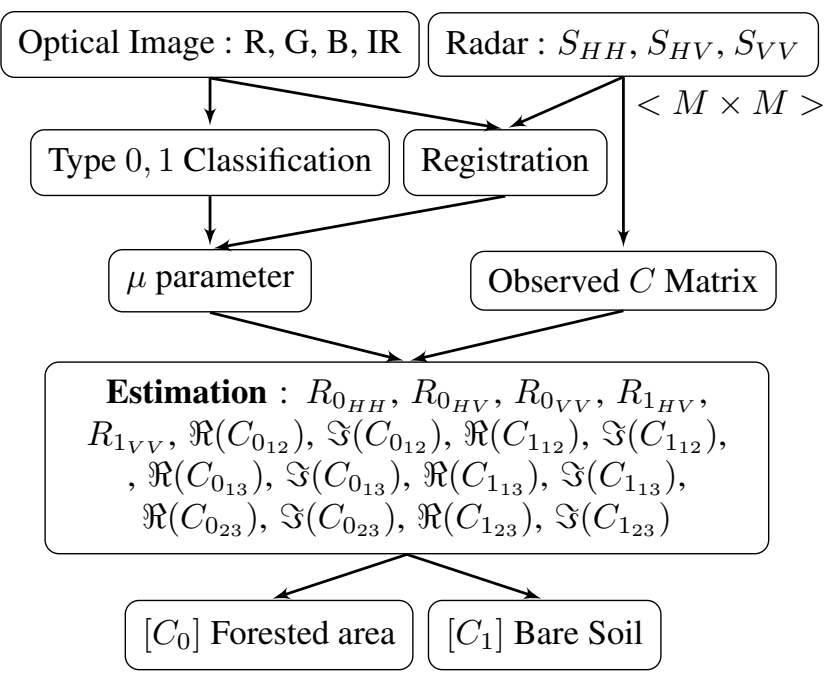

Fig. 1: Unmixing Algorithm

cultural decline so that the area contained different local $\mu$ conditions.

The Pauli decomposition was used to assess if the reconstructed $C$ matrix is relevant with the observations. Figure 2 shows the study zone using an optical NDVI and the observed Pauli decomposition. Validation of the unmixed algorithm was performed based on transects on natural transition between the two land cover types. Pauli volume, double-bounce and surface scattering obtained from the reconstructed covariance matrix (equation 2) and from the observed covariance matrix were compared. The transect points out that the linear unmixing equations detailed in section 2 provide Pauli parameters relevant with the observations. Numerical assessment of residual was performed in table 1. Correlation coefficients between elements of the observed and reconstructed $C$ matrix validate the unmixing approach. Diagonal terms are particularly well reconstructed whereas non-diagonal terms seem to be slightly biased.

Table 1: Statistical assessment of the unmixing

\begin{tabular}{ccccccc}
\hline & $\Delta C_{11}$ & $\Delta C_{12}$ & $\Delta C_{13}$ & $\Delta C_{22}$ & $\Delta C_{23}$ & $\Delta C_{33}$ \\
\hline mean & 0.104 & 1.118 & 0.213 & 0.102 & 1.082 & 0.100 \\
$\sigma$ & 0.082 & 1.992 & 0.127 & 0.079 & 1.452 & 0.081 \\
\hline & $C_{11}$ & $C_{12}$ & $C_{13}$ & $C_{22}$ & $C_{23}$ & $C_{33}$ \\
\hline$\rho(o, r)$ & 0.934 & 0.834 & 0.913 & 0.946 & 0.847 & 0.937 \\
\hline
\end{tabular}

$$
\begin{gathered}
\text { with } \Delta C_{i j}=\left|\frac{C_{i j} \text { observed }-C_{i j} \text { reconstructed }}{C_{i j} \text { reconstructed }}\right| \\
\text { and } \rho(o, r)=\frac{\operatorname{cov}\left(\mid C_{i j} \text { observed }|,| C_{i j} \text { reconstructed } \mid\right)}{\sigma\left(\mid C_{i j} \text { observed } \mid\right) \sigma\left(\mid C_{i j} \text { reconstructed } \mid\right)}
\end{gathered}
$$




$$
\begin{aligned}
& {[C]=\mu\left[C_{0}\right]+(1-\mu)\left[C_{1}\right]} \\
& \text { with } C_{0}=\left[\begin{array}{ccc}
R_{0_{H H}} & \sqrt{2} R_{0_{H H} H} e^{j\left(\Delta \phi_{0_{H H}-H V}\right)} & R_{0_{H H V V}} e^{j\left(\Delta \phi_{0_{H H}-V V}\right)} \\
\sqrt{2} R_{0_{H H H V}} e^{j\left(-\Delta \phi_{0_{H H}-H V}\right)} & 2 R_{0_{H V}} & \sqrt{2} R_{0_{H V V V}} e^{j\left(\Delta \phi_{0_{H V}-V V}\right)} \\
R_{0_{H H V V}} e^{j\left(-\Delta \phi_{0_{H H-V V}}\right)} & \sqrt{2} R_{0_{H V V V}} e^{j\left(-\Delta \phi_{0_{H V}-V V}\right)} & R_{0_{V V}}
\end{array}\right] \\
& \text { and } C_{1}=\left[\begin{array}{ccc}
R_{1_{H H}} & \sqrt{2} R_{1_{H H} H V} e^{j\left(\Delta \phi_{1_{H H-H V}}\right)} & R_{1_{H H V V}} e^{j\left(\Delta \phi_{1_{H H-V V}}\right)} \\
\sqrt{2} R_{1_{H H} V} e^{j\left(-\Delta \phi_{1_{H H}-H V}\right)} & 2 R_{1_{H V}} & \sqrt{2} R_{1_{H V V V}} e^{j\left(\Delta \phi_{1_{H V}-V V}\right)} \\
R_{1_{H H V V}} e^{j\left(-\Delta \phi_{1_{H H}-V V}\right)} & \sqrt{2} R_{1_{H V V}} e^{j\left(-\Delta \phi_{1_{H V}-V V}\right)} & R_{1_{V V}}
\end{array}\right]
\end{aligned}
$$

by using the following notation, $X Y X^{\prime} Y^{\prime}=\{H H H V, H H V V, H V V V\}$ :

$$
\begin{cases}R_{0_{X Y}} & =E\left(\sum_{n=1}^{N}\left|S_{0 n_{X Y}}\right|^{2}\right) \\ R_{1_{X Y}} & =E\left(\sum_{n=1}^{N}\left|S_{1 m_{X Y}}\right|^{2}\right) \\ R_{0_{X Y X^{\prime} Y^{\prime}}} & =E\left(\sum_{n=1}^{N}\left|S_{0 n_{X Y}}\right|\left|S_{0 n_{X^{\prime} Y^{\prime}}}\right|\right) \\ R_{1_{X Y X^{\prime} Y^{\prime}}} & =E\left(\sum_{n=1}^{N}\left|S_{1 m_{X Y}}\right|\left|S_{1 m_{X^{\prime} Y^{\prime}}}\right|\right) \\ \Delta \phi_{0_{X Y-X^{\prime} Y^{\prime}}} & \text { such as } \left.\cos \left(\Delta \phi_{0 X Y-X^{\prime} Y^{\prime}}\right)=E\left(\cos \left(\phi_{0 n_{X Y}}-\phi_{0 n_{X^{\prime} Y^{\prime}}}\right)\right)\right) \\ \Delta \phi_{1_{X Y-X^{\prime} Y^{\prime}}} & \text { such as } \left.\quad \cos \left(\Delta \phi_{1_{X Y-X^{\prime} Y^{\prime}}}\right)=E\left(\cos \left(\phi_{1 m_{X Y}}-\phi_{1 m_{X^{\prime} Y^{\prime}}}\right)\right)\right)\end{cases}
$$
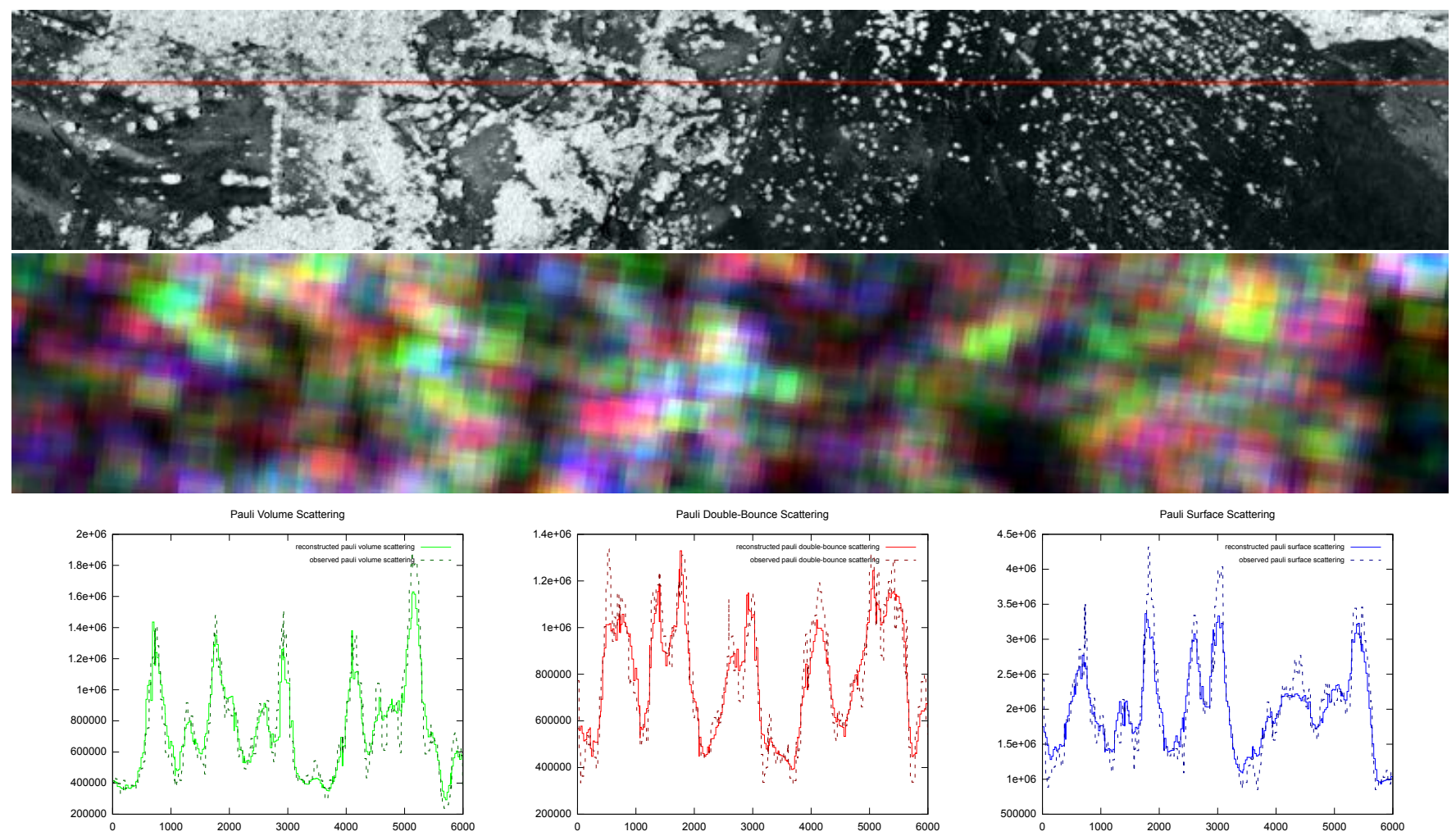

Fig. 2: Optical NDVI, Observed Pauli Decomposition, and Observed and Reconstructed Pauli volume, double-bounce and surface scattering based on a transect 


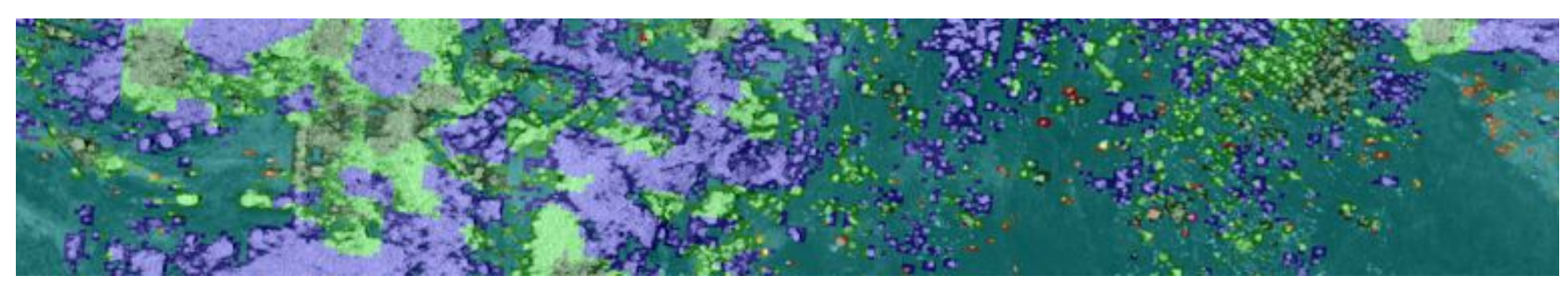

$H_{0} / \alpha_{0}$ segmentation types from $T_{0}$ (from $C_{0}$ )

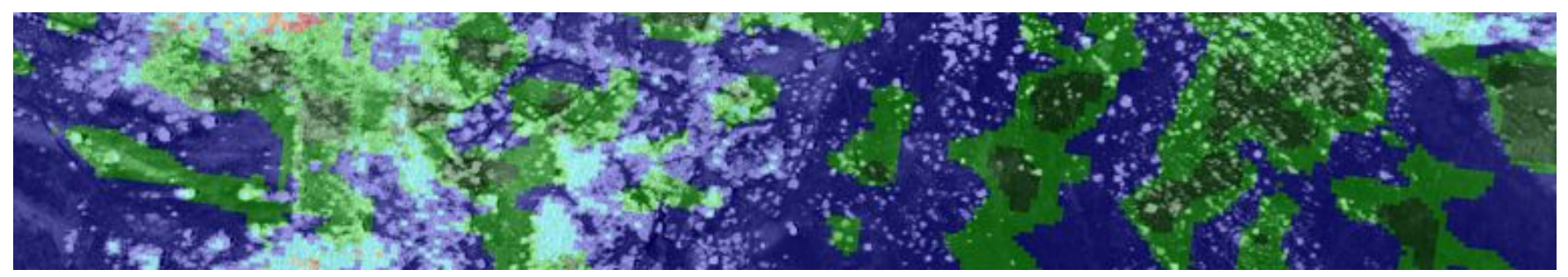

$H_{1} / \alpha_{1}$ segmentation types from $T_{1}$ (from $C_{1}$ )

\begin{tabular}{|l|l|l|l|l|l|l|l|l|l|}
$H / \alpha$ segmentation types ([3]): & $\mathbf{1}$ & $\mathbf{2}$ & $\mathbf{3}$ & 4 & $\mathbf{5}$ & $\mathbf{6}$ & $\mathbf{7}$ & $\mathbf{8}$ & $\mathbf{9}$ \\
\hline
\end{tabular}

Fig. 3: $H / \alpha$ segmentation types, NDVI overlay

\section{PERSPECTIVES}

Having pointed out that the linear unmixing model is able to split off polarimetric information on a land cover type basis, the information contained in the $C_{0}$ and $C_{1}$ matrices has to be assessed.

The $H / \alpha$ segmentation of the Cloude and Pottier decomposition [3] was performed to evaluate the type of information obtained with the unmixing. Segmentation types derived from the type 0 and 1 are shown in figure 3 .

Validation tests have to be carried out to assess whether the unmixed product can produce more reliable results for large scale land cover classifications. In a first approach, $H_{0} / \alpha_{0}$ segmentation types show different behaviours for forested area: volume (type 5 and 6 ) and surface scattering (type 8). Moreover segmentation types 1, 2, 3 and 4 appear on isolated trees. This type of information is not visible decomposing the observed $C$ matrix. For bare soil, $H_{1} / \alpha_{1}$ segmentation types can as well point out volume or surface scattering areas.

In order to continue with validation, the $C_{0}$ and $C_{1}$ elements obtained without any supervision will be compared to the elements of observed $C$ matrix in non-mixed conditions. We hope to prove the unmixing algorithm have produced greater information for land cover, so that $C_{0}$ and $C_{1}$ can distinguish better between land cover types than the observed $C$ matrix. Then, a detailed spatial analysis of the residuals is currently carried out. Preliminary results show small areas where higher residuals are observed. As a consequence, we will considerer to extend the equations to $n$ types of land cover classes, and we will investigate if the higher residuals may be linked to the number of land cover classes.

Finally, the algorithm could be tested on different land cover classes and different radar wavelength. For example, the case of L-band radar may be interesting for forested and semi-natural areas.

\section{REFERENCES}

[1] S. Giordano, G. Mercier, and J.-P. Rudant, "A proposed framework to unmix scattering mechanisms of polarimetric radar images using very high resolution optical images," ISPRS Annals of Photogrammetry, Remote Sensing and Spatial Information Sciences, vol. I-7, pp. 279-284, 2012.

[2] S. R. Cloude and E. Pottier, "A review of target decomposition theorems in radar polarimetry," IEEE Transactions on Geoscience and Remote Sensing, vol. 34, no. 2, pp. 498-518, Mar. 1996.

[3] S. R. Cloude and E. Pottier, "An entropy based classification scheme for land applications of polarimetric SAR.," IEEE Transactions on Geoscience and Remote Sensing, vol. 35, no. 1, pp. 68-78, 1997.

[4] J. W. Goodman, "Statistical properties of laser speckle patterns," Laser speckle and related phenomena, vol. 9, pp. 9-75, 1975. 